\title{
PRÁTICAS PEDAGÓGICAS SOB AS LENTES DE UMA PROFESSORA FORMADORA DO PROGRAMA PACTO NACIONAL PELA ALFABETIZAÇÃO NA IDADE CERTA- PNAIC $^{1}$
}

Ivete Brito e Brito *

Resumo: O artigo apresenta o registro narrativo de experiências vividas como Professora Formadora de um Programa de Formação de Professores do governo federal, PNAIC (Programa Nacional de Alfabetização na Idade Certa). Sua ênfase recai sobre a constituição de professoras alfabetizadoras, suas práticas pedagógicas, suas multiplicidades e mergulhos em práticas inventivas a partir suas experiências formativas no PNAIC. Tomando como ferramentas analíticas as teorizações de Michel Foucault acerca dos processos de subjetivação esse artigo convida a pensar sobre os lugares ocupados pelas professoras nos Programas sobre Formação de Professores. Dentre as vivências narradas destaca-se a aproximação com duas professoras de escolas do Ensino Fundamental do interior do Pará que permitem visualizar os modos de ser professora, modos de ação e formação docente a constituir regimes de verdades que qualificam, demarcam, incluem e excluem docentes, mas que também permitem lançar-se ao encontro do novo, resistindo e inventando práticas pedagógicas.

Palavras-chave: Formação de professores. Subjetividade. Verdade.

Introdução

Form(a)ção em movimentos, de onde falo...

O presente trabalho origina-se de meus registros como professora formadora do Programa do governo federal Pacto pela Alfabetização na Idade Certa (PNAIC) e sistematiza encontros que descrevem as práticas pedagógicas e constituição de professoras alfabetizadoras. Tem relevância por trazer reflexões sobre os encontros e eventos onde foi possível presenciar as práticas pedagógicas em diferentes contextos escolares do interior do Estado do Pará.

As aproximações com salas de aulas, práticas pedagógicas e as concepções dos alunos possibilitam trazer reflexões sobre contextos, formas, vivências e os modos de ver e ser que estamos acostumados a impor como verdades.

Nas próximas linhas descrevo como foi o processo para acontecer os encontros através do programa PNAIC, as viagens e impressões que ficaram marcados no processo de ensinoaprendizagem em uma professora formadora.

\footnotetext{
${ }^{1}$ Texto produzido a partir de registros narrativos de experiências vividas como Professora Formadora do PNAIC sobre as práticas pedagógicas de professoras alfabetizadoras.

*Pedagoga, Mestre em Ensino de Ciências e Matemáticas, é professora da Escola de Aplicação da Universidade Federal do Pará (UFPA). britoivete15@gmail.com
} 
Como professora formadora, além de ministrar as "Formações", realizava acompanhamento, que chamamos de "visitas", às professoras alfabetizadoras. Essas visitas tem caráter de acompanhamento, incentivo e também de verificação sobre como a formação do Programa PNAIC estava sendo trabalhada em sala de aula.

Embora o trabalho de Formação, em seus aspectos formais, nos apresentem ricas discussões, não pretendo neste momento adentrar nesta ceara, mas gostaria de falar do lugar que ocupo de quem já esteve na posição de aluna, professora dos anos inicias, e hoje está como Formadora de um Programa de Formação Continuada, dialogando com as professoras sobre suas práticas pedagógicas e o ensino no ciclo de alfabetização.

\section{Caracterização dos locais visitados}

A experiência aqui descrita narra vivências em visitas a salas de aula de professoras alfabetizadoras dos municípios de Peixe-Boi, situado na região nordeste, e Breves, na região do Marajó, ambas do Estado do Pará. As escolas visitadas fazem parte da rede Municipal de ensino em área urbana e do campo, com turmas de 1으 ao 4으 ano. As professoras são pedagogas e possuem pouco tempo de formação embora já estejam atuando a mais de cinco anos neste nível de ensino. A escola visitada no município de Peixe-Boi localiza-se na zona urbana em um bairro médio da cidade e tem características físicas comuns. A escola do Município de Breves/Marajó localiza-se no rio Macaco, é uma palafita que tem o rio como rua e tem estrutura de madeira.

Meu contato com as professoras dos anos iniciais não acontecia no primeiro momento da organização do programa PNAIC, ou seja, as formações eram direcionadas primeiramente aos técnicos responsáveis pelo programa nos municípios, em seguida os técnicos repassavam a formação aos professores dos anos iniciais, só então os formadores realizavam visitas aos professores para conversar, reforçar, tirar dúvidas e incentivar o trabalho com a proposta do programa PNAIC.

É sobre este momento de realização das visitas aos professores dos anos iniciais que me debruço para contar um pouco das tantas histórias, vivências, e experiências sobre práticas pedagógicas, didáticas e constituição de professores que venho acumulando ao longo destes dois anos como Professora Formadora.

Sobre os conceitos de verdade e subjetividade

Para compreendermos os jogos de verdade que constituem a trama que fabrica a subjetividade das professoras é necessário nos mantermos longe de tudo que remete à ideia de origem 
e entender a ideia de verdade como "[...] um conjunto de procedimentos regulados para a produção, a lei, a repartição, a circulação e o funcionamento dos enunciados" (FOUCAULT, 2010, p. 14). Sob as lentes de Foucault é possível ver historicamente como se produzem efeitos de verdade no interior de discursos que não são em si nem verdadeiros, nem falsos. Foucault $(2010$, p. 12) nos ajuda a pensar que a verdade das chamadas competências, habilidades e também das necessidades formativas dos professores é produzida em cada momento histórico e faz parte do que articula a trama dessa produção e a constituição de subjetividades nas relações de poder e saber.

Quanto ao conceito de subjetivação, é possível dizer que, em um primeiro sentido, Foucault nos fala dos modos de subjetivação como modos de objetificação, ou seja, modos que, por exemplo, os professores podem aparecer como objetos de uma determinada relação de conhecimento e de poder. Sendo que esses modos de subjetivação e de objetificação não são independentes uns dos outros, mas se desenvolvem ao mesmo tempo.

\section{Descrevendo as experiências}

\section{Práticas Pedagógicas de professoras alfabetizadoras}

As visitas que me levavam a estar nas salas de aulas com as professoras alfabetizadoras e as crianças dos anos iniciais, ao mesmo tempo em que me faziam ser sempre outra após o vivido, me permitiram observar e pensar a formação de professores e os movimentos que a educação (des)constrói nas vidas envolvidas. Mas, a princípio, sob minhas lentes era muito "natural" perscrutar com os alunos e com os professores sobre a leitura, a escrita e o cálculo, ou seja, as competências e habilidades de disciplinas como linguagem e matemática, que têm maior cobrança de resultados nas provas que fazem a avaliação do processo ensino-aprendizagem.

Nesta dinâmica, durante muito tempo observei se os alunos estavam lendo, escrevendo e contando, ou seja, se estavam alfabetizados e numeralizados, sem estranhar ou questionar sobre como as práticas pedagógicas estavam sendo desafiadas dentro de cada contexto.

A partir de leituras que me fizeram desconfiar das "verdades" que operam delimitando o que tem mais relevo no ensino em função do que será cobrado, passei a minha inquietude diante das reclamações das professoras sobre a pressão para que as turmas obtivessem bons resultados nas provas de avaliação do desenvolvimento do ensino que viriam ao final do ano.

Deparei-me diante de uma dessas professoras ao entrar em uma sala de aula no município de Peixe Boi, localizado no nordeste do Pará, onde conversei e brinquei com os alunos e em seguida conversei com a professora sobre o trabalho pedagógico com as disciplinas. Neste momento a 
professora, ressaltando suas dificuldades com o tempo e a pressão para dar conta dos conteúdos aos quais seriam cobrados, ou leitura, escrita e cálculo, foi direta e clara ao dizer:

-Minha preocupação e empenho é que pelo ao menos os alunos consigam ler e escrever! $O$ resto eles aprendem depois, porque não dá tempo!

Minha reação diante da professora foi de paralisia e reflexão sobre o que eu também já havia vivido como professora e aluna. Como professora, revisitei minhas memórias de ter vivido tal pressão e preocupação. Tal verdade que a professora contou viver naquele momento, e que eu tive como minha no lugar que ocupei como professora, provoca a reflexão sobre a questão das múltiplas verdades que atribuem em determinado momento prioridade a uns conhecimentos em detrimento de outros, verdades que "são produzidas com múltiplas coerções e produz efeitos regulamentados de poder", não um poder que usa a força ou proibição, mas que "deve-se considerá-lo como uma rede produtiva que atravessa todo o corpo social muito mais do que uma instância negativa que tem por função reprimir" (FOUCAULT, 2010, p.7 e 10).

\section{Práticas Pedagógicas no Cotidiano}

A maior riqueza do homem é sua incompletude. Nesse ponto sou abastado. Palavras que me aceitam como sou - eu não aceito. Não aguento ser apenas um sujeito que abre portas, que puxa válvulas, que olha o relógio, que compra pão às 6 da tarde, que vai lá fora, que aponta lápis, que vê a uva etc. etc. Perdoai. Mas eu preciso ser outros. Eu penso renovar o homem usando borboletas. (Manoel de Barros, 2013, p. 347).

Com a poesia de Manoel de Barros é possível pensar as experiências, que baseadas nas percepções, possibilitaram aprender sobre as multiplicidades das identidades construídas, mas também permite refletir sobre a nossa incompletude enquanto subjetividades constituídas com um repertório de representações que projetadas no contexto vivido tem sua produção de sentido. Assim, com as lentes de quem vivenciou e hoje desconfia de tais construções quando se colocam como únicas, passei a observar as professoras, durante as visitas, em seus movimentos de resistência quando não aceitam o enquadramento identitário fixo e inventam práticas pedagógicas operando simultaneamente com as prescrições que ditam os modos de ser e fazer do professor.

Entendendo que o processo de construção de subjetividades das professoras é múltiplo e complexo, não ousei tentar compreender tal complexidade, mas me coloquei a tentar ver e sentir o que acontece em uma escola dos anos iniciais do ensino fundamental, desta vez, no Município de Breves/Marajó, localizado no interior do Pará, a respeito das práticas pedagógicas no ciclo de alfabetização. 
Nesta escola só é possível chegar através de transporte fluvial, tendo crianças e professoras como principal meio de transporte canoas ou pequenos barcos a motor. Sendo assim, o rio é a rua que passa em frente à escola com as variações das marés e uma visão de um grande rio que aparenta não ter fim. Nas laterais da escola e ao fundo há inúmeras árvores frutíferas e vegetações variadas que dão o ar de solitude à escola naquela paisagem.

No contato com a escola encontrei uma única professora que no primeiro momento informou que atuava em todas as frentes de trabalho que a escola necessitava, como servente, zeladora, professora e outros. Tal realidade não é uma novidade na educação na Amazônia e não é meu interesse levantar questões sobre as condições de trabalho, mas quero tratar das experiências e forças que transitam no campo da educação enquanto currículo vivo e que produzem efeitos na prática pedagógica com conhecimentos que estão dispostos na vivência principalmente do aluno do campo.

Estávamos no fim do mês de outubro de 2016 e minha chegada à escola coincidiu com a saída dos alunos, o que me possibilitou observá-los fora de sala de aula e no retorno para suas casas. Sentei-me em um banco próximo a sala de aula e me coloquei a observar o movimento dos alunos. De forma "arteira" uns subiam na árvore de goiabeira para comer a fruta, outros se encaminhavam para a canoa, nas quais remavam até a escola, outros corriam para uma área atrás da escola para jogar bola e outros se sentaram ao meu lado cheios de curiosidade.

Aproveitando a curiosidade dos alunos iniciei uma conversa me apresentando e perguntando se estudavam ciências da natureza e obtive a seguinte resposta:

- Estudamos sim, a ciência da natureza está em tudo isso! Nesse rio imenso, na fruta que é nossa merenda, na nossa remada de canoa e até na capina do quintal da escola que a gente joga bola (risos).

A resposta dos alunos despertou minha curiosidade de conversar com a professora a respeito de suas práticas de ensino que faziam os alunos ver o ensino de ciências da natureza em suas vivências e práticas cotidianas de forma tão natural. Após alguns minutos tive a oportunidade de conversar com a professora, que de forma envergonhada disse que suas práticas talvez não fossem certas porque não eram somente dos livros didáticos ou através de provas, mas que ainda assim as crianças aprendiam.

Ainda em conversa com a professora, ela descreveu que ensinava todo o conteúdo de ciências da natureza fazendo atividades práticas como apanhar as frutas para a merenda problematizando as estações do ano e de colheita, a importância da alimentação saudável, fazendo passeios de canoa conversando sobre as marés, os peixes, tipos de animais, e limpando o quintal da escola contando sobre diversos conteúdos e também porque era o local em que seria comemorado o 
dia das crianças dos alunos. Ao ouvir a professora fui surpreendida com uma batida em minhas pernas de uma bola de sacos plásticos, que no mesmo momento os alunos disseram com orgulho: "Foi à gente que fez!".

O diálogo com os alunos mostrou o quanto eles conseguem estabelecer a relação entre conhecimentos escolares com o que é vivido no cotidiano, no quintal da escola onde construíram seu campo de futebol e confeccionaram sua bola. As práticas pedagógicas da professora se mostraram integradas/inventadas no contexto e com o desejo de significar o ensino em um processo de criação que produz a imagem, as palavras, os gestos, um modo de existência e formas de expressão sobre os saberes escolares e a dimensão do ensino (CHAVES, 2013).

\section{Avaliação}

As experiências descritas permitem diagnosticar e refletir que para avaliar contextos e processos não basta apenas a coleta de dados sobre dos saberes escolares específicos, mas como diz Luckesi (2011, p.285) "para explicar e compreender o que ocorre com a aprendizagem, importa ter presente as variáveis intervenientes, que atuam nos resultados".

Entre as múltiplas variáveis do processo de ensino-aprendizagem é preciso pensar na constituição de professores e alunos, suas leituras de mundo, seus contextos e os que os move como verdade.

\section{Considerações finais}

Os modos de existência e inventividade de práticas pedagógicas que são criadas pelas professoras dos municípios de Peixe Boi e de Breves no âmbito das possibilidades do ensino escolar mostram as multiplicidades em que estão envolvidas as construções de subjetividades das professoras.

Com essa compressão destaco que não se trata de comparar as práticas e modos de existência como certos ou errados, mas de mostrar que não há verdades únicas e fixas. Que em cada lugar ocupado, há movimentos e fluxos que produzem a potência do desejo e o desvia de uma ação tímida para seu destino criador que se faz nos entre-dois dos discursos ou uma ação que se lança inventando e artistando práticas e modos de ser professora, sendo sempre outra e, como diz Manoel de Barros, pensando em renovar usando borboletas. 


\title{
PEDAGOGICAL PRACTICES UNDER THE LENSES OF A TEACHER FORMATING THE NATIONAL COVENANT PROGRAM FOR LITERACY IN THE CERTA-PNAIC AGE
}

\begin{abstract}
The article presents the narrative record of experiences lived as Teacher Formator of a Teacher Training Program of the federal government, PNAIC (National Literacy Program in the Right Age). Its emphasis is on the constitution of literacy teachers, their pedagogical practices, their multiplicities and immersions in inventive practices from their formative experiences in the PNAIC. Taking as analytical tools Michel Foucault's theories about the processes of subjectivation, this article invites us to think about the places occupied by the teachers in the Teacher Training Programs. Among the narrated experiences is the approach with two primary school teachers from the interior of Pará that allow to visualize the ways of being a teacher, modes of action and teacher training to constitute regimes of truths that qualify, demarcate, include and exclude teachers, but also allow us to launch a meeting with the new, resisting and inventing pedagogical practices in literacy teaching.
\end{abstract}

Keywords: Teacher training. Subjectivity. Truth. teachers, practices.

\section{Referências}

BARROS, Manoel de. Poesia completa. São Paulo: Leya, 2013.

CHAVES, Silvia. N. Reencantar a ciência, reinventar a docência. São Paulo: Editora Livraria da Física, 2013.

FOUCAULT, Michel. Verdade e poder. In: FOUCAULT, Michel. Microfísica do Poder. Rio de Janeiro: Graal, 2010, pp. 1 -14.

LUCKESI, Cipriano Carlos. Avaliação da aprendizagem componente do ato pedagógico. 1ํㅡ. Ed. São Paulo: Cortez, 2011. 